\title{
Synthesis, Characterization of some gabapentin derivatives by Green Chemistry
}

\author{
Dhafir M. Husain Al-Mudhaffar \\ Nahid H. Rishag \\ Chemistry Department, Science College \\ Basrah University \\ Iraq
}

\begin{abstract}
Two new gabapentin derivatives were synthesized without solvent as green chemistry, by mixing gabapentin with sebacoylchioride in (2:1) molal ratio to give derivative (1). The second derivative(2)was synthesized by mixing one mole of benzoyl chloride with one mole of gabapentin without solvent. These derivatives(1) and (2)which act as ligands, were characterized by FT-IR, CHN, ${ }^{1} H N M R,{ }^{13} C N M R$ measurements and thermal analysis. Complexes of gabapentin derivatives were prepared by adding $\mathrm{MNO}^{3} .3 \mathrm{H}_{2} \mathrm{O}$, where $\mathrm{M}=\mathrm{Cu}(\mathrm{II})$, to gabapentin derivatives (1) in 2:1molal ratio and to derivative (2) in 1: 2 molal ratio of $\mathrm{Cu}(\mathrm{II})$ to the derivative (2). The complexes(3)and(4)have been characterized by FT-IR, CHN and thermal analysis.
\end{abstract}

Keywords: Gabapentin, benzoyl chloride, sebacoyl chloride, copper(II) nitrate, green chemistry.

\section{Introduction}

Gabapentin is a medication which is used to treat partial seizers, neuropathic pain, hot flashing and restlesslegs syndrome (Goa KL et al,1993),(Goa KL, et al 2015), (Wijemanna S.et al, 2015). Many gabapentin derivatives have been synthesized and studied (Shokohi-pour Z,2016),(Ahmad N.,Senwell D. 2017), ( Husain E.A., Kanwal, N. et al, 2017), ( Hekmat S.et al, 2017). Unprecedented example of metal complexes with 1-aminomethyl-1-cyclohexane acetic acid were synthesized and giving $\mathrm{Co}(\mathrm{Gbn} .)_{4}$ and $\mathrm{Ni}(\mathrm{Gbn}$.) complexes, and the study revealed that cobalt complex has better activity than gabapentin(11a)(Amshumali MK et al Jan 2018). Recently another gabapentin derivatives were synthesized by condensation of gabapentin with some acid chlorides, and showed some antibacterial activities and antioxidant properties (Al-Mudhaffar Dh. et al, 2018).

Nitroalkane- gabapentin derivatives have been predicted (Amirani M. \& Mahamnade M., 2018). A new gabapentinbase synthesis and theoretical studies of active compound ; N-cyclohexyl-3- oxo-2-(3-oxo-2-azospiro[4,5] decan-2-yl)3-aryipropanamids and $\mathrm{N}$-(tert-butyl)-2-(3-oxo-2-azospiro[4,5]decan-2-yl)-2-arylacetamide derivatives have been reported( MahboobAmericaniPoor et al2018).Unpresented example of metal complexes with 1-aminomethyl cyclohexane acetic acid was reported(Amshumali MK, et al, Jan 2018).

Another example of gabapentin derivatives which have been synthesized by green chemistry and facile reaction with sulfonide chlorides to produce lactams and sulfonamides derivatives (11) had been achieved (Hussain Erum A. et al March 2018).

In the current article, we have synthesized, by a greenchemistry, two new gabapentin derivatives by condensation of gabapentin directly, without solvent, with two acid chlorides and preparing their $\mathrm{Cu}(\mathrm{II})$ - complexes.

\section{Experimental}

\subsection{Materials:}

Gabapentin was from (Actavis). $\mathrm{CuCl}_{2} \cdot 2 \mathrm{H}_{2} \mathrm{O}$ was from $(\mathrm{BDH}) . \mathrm{CCl}_{4}$ was from (BDH) and used without further purification.Sebacoyl Chloride was from Alpha Aldrich. BenzoylChloridewas from (Merck).Silica gel60F254 aluminum TLC sheets were supplied by Merck.

\subsection{Physical measurements:}

Melting points were done by using Gallenkamp apparatus .Infra-red spectra were reported on shimadzu spectrophotometer in the range 4000-400 $\mathrm{cm}^{-1}$ with $\mathrm{KBr}$ disc. Thermal analysis, (TGA and DTG) were done by using TGA 4000, PerkinElmer by heating from $30^{\circ} \mathrm{C}$ to $900^{\circ} \mathrm{Cat} 40.0^{\circ} \mathrm{C} \mathrm{lmin}$. heating rate with alumina crucible.

Elemental analysis were performed on a Vario EL cube apparatus.NMR spectra were reportedon a Bruker spectrometer at $300 \mathrm{MHz}$ by using TMS as reference and in DMSO as a solvent. 


\subsection{Synthesis of gabapentin derivatives:}

\subsection{1. (Sebacoyl - gabapentin) derivative (1):}

(0.242 gm; 2mmol) of gabapentin (gabn.) was mixed with $(0.239 \mathrm{gm} ; 1 \mathrm{mmol})$ of sebacoyl chloride and mixed by stirringwithout solvent at $50^{\circ} \mathrm{C}$ for $1 \mathrm{hr}$. Then the white resultant mixture Solid was washed with $\mathrm{CCl}_{4}$ many times and followed by TLC in (2:1 ) ratio for (Ethanol: $\left.\mathrm{CCl}_{4}\right)$, giving white solid (76\% yield ), m.p.:(96-98) C, then was kept in a desiccator.

\subsection{2. (Benzoyl- gabapentin) derivative (2):}

Similar procedure was done as in (2.3.1) by mixing $(0.1710$ gm.; 1 mmol $)$ gabapentin (gabn.) with $(0.1350$ gm ; 1 mmol) benzoyl chloride without solvent and stirred for $1 \mathrm{hr}$. Then was worked up as in (2.3.1) giving white solid(m.p.: 98-100) $\mathrm{C}$, (76\% yield), then was kept in desiccator.

\subsubsection{Preparation of $\mathrm{Cu}$ (II)-(Sebacoyl- gabapentin) derivative)complex (3):}

( $0.100 \mathrm{gm}: 0.50 \mathrm{mmol})$ of the derivative (1)was added to basic solution of $\mathrm{Cu}(\mathrm{NO} 3) 2.3 \mathrm{H} 2 \mathrm{O}(0.240 \mathrm{gm}, 1 \mathrm{mmol})$ which dissolved in minimum volume of distilled water, and the mixture was stirred at room temperature till completion by following with TLC giving a green precipitate.The resultant precipitate was filtered and washed many times with water,and the resultant green solid was dried and kept in desiccator,(72\% yield).

\subsubsection{Cu (II)-(Benzoyl- gabapentin) derivative complex (4):}

Similar procedure was done as in (2.3.3) above to prepare this complex by mixing ( $0.0550 \mathrm{gm}$ : $0.2 \mathrm{mmol})$ of benzoylgabapentin derivative (1)with hydrated Cupric nitrate ( $0.0241 \mathrm{gm:} 1 \mathrm{mmol}$ ) dissolved in minimum volume of distilled water and giving green solution and worked up as above item(2.3.3) to give a green solid and was kept in a desiccator. (67\% yield)

\section{Results and discussions:}

\subsection{Infra- red spectra:}

In case of sebacoyl-gabapentin derivative (1)gives band at $1697.41 \mathrm{~cm}^{-1}$ which is attributed to carbonyl group due to the formation of amide group beside the disappearance of (NH2) bands of gabapentin that appear at $2857 \mathrm{~cm}^{-1}$ and 2931 $\mathrm{cm}^{-1}$ and appearance $\mathrm{NH}$ of amide group at $3398.69 \mathrm{~cm}^{-1}$. On complexation of this derivative (1) with $\mathrm{Cu}$ (II) ion the resultant infrared spectrum is similar to that of gabapentin derivative (1) except the disappearance of $\mathrm{OH}$ band of gabapentinand shift of amide carbonyl stretching frequency to $1697.4 \mathrm{~cm}^{-1}$, indicating the coordination of $\mathrm{Cu}(\mathrm{II})$ ion with oxygen atom of carboxylic group of gabapentin.

Infra-red spectrum of the synthesized benzoyl-gabapentin derivative (2)shows theidentical spectral bands as that of gabapentin and benzoyl chloride alone, but with additional bands at about $1678 \mathrm{~cm}^{-1}$ attributed to $v_{\mathrm{c}=\mathrm{o}}$ of amide group which is formed due to condensation of benzoyl chloride with gabapentin ( Al- Mudhaffar Dh. 2018), and disappearance of $\left(\mathrm{NH}_{2}\right)$ band of gabapentin. This givesan indication of the formation of the amide derivative compound (1).And on complexation of this derivative $(\mathbf{1})$ with $\mathrm{Cu}^{2+}$ ion, the $\mathrm{OH}$ band disappeared as a result of coordination of the metal ion with oxygen atom of carboxylic group in basic medium in formation of complex compound (3).

\subsection{Elemental analysis:}

Elemental analyses (CHN data)of the prepared compounds indicated the formation of bidentate ligands $(\mathbf{1} \& \mathbf{2})$, in addition to formation four coordination complexes containing one ligand of gabapentin derivative ( $\mathbf{3}$ ) and two ligands of the second gabapentin derivative(4), as as shown in Table (1). Table 1: CHN and some physical properties of compounds $(1,2,3 \& 4)$

\begin{tabular}{|c|l|l|l|l|l|l|}
\hline Symbol & Molecular formula & $\begin{array}{l}\text { m.p. } \\
\text { C }\end{array}$ & Color & $\begin{array}{l}\text { Founded } \\
\text { (Theoretical) } \\
\% \mathrm{C}\end{array}$ & $\begin{array}{l}\text { Founded } \\
\text { (Theoretical) } \\
\% \mathrm{H}\end{array}$ & $\begin{array}{c}\text { Founded } \\
\text { (Theoretical) } \\
\% \mathrm{~N}\end{array}$ \\
\hline 1 & $\mathrm{C}_{28} \mathrm{H}_{48} \mathrm{~N}_{2} \mathrm{O}_{6}$ & -96 & White & 66.0615 & 9.3572 & 5.3281 \\
& 98 & & $(66.1085)$ & $(9.5112)$ & $(5.5068)$ \\
\hline 2 & $\mathrm{C}_{16} \mathrm{H}_{21} \mathrm{NO}_{3}$ & -98 & White & 69.5682 & 7.4297 & 4.8299 \\
& & 100 & & $(69.7931)$ & $(7.6878)$ & $(5.0870)$ \\
\hline 3 & $\mathrm{Cu}\left(\mathrm{C}_{28} \mathrm{H}_{46} \mathrm{~N}_{2} \mathrm{O}_{6}\right)$ & $>300$ & Green & 66.0004 & 8.9061 & 5.4608 \\
& & & & $(66.3002)$ & $(9.1413)$ & $(5.5223)$ \\
\hline 4 & $\mathrm{Cu}\left(\mathrm{C}_{16} \mathrm{H}_{20} \mathrm{NO}_{3}\right)_{2}$ & $>300$ & Green & $\begin{array}{l}62.8047 \\
(62.9860)\end{array}$ & $\begin{array}{l}6.4168 \\
(6.6076)\end{array}$ & $\begin{array}{l}4.3822 \\
(4.5908)\end{array}$ \\
\hline
\end{tabular}




\subsection{Thermal analysis:}

Thermal analysis hadbeen done for the two derivatives (1) and (2) and their $\mathrm{Cu}(\mathrm{II})$ complexes (3\& 4), as shown in the Figs. (1,2,3\& 4):

\subsubsection{Sebacoyl- gabapentin derivative (1):}

This derivative shows one step weight loss (wt. loss) at $314.55{ }^{\circ} \mathrm{C}$ of $91.717 \%$ as practical wtloss, with complete breakdown of the compound (1), but leaving radical as $\mathrm{C}_{2} \mathrm{O}_{2}$ (ethene-1,2-dione)corresponding to $56 \mathrm{~g}$ Imol and the theoretical wt. loss value is $88.99 \%$ which is nearly equal the practical one, leaving char residue with $8.02 \%$ wt. of the derivative (1), at $361.36^{\circ} \mathrm{C}$. The TGA gives one step with one DTG band as in Fig.(1), and according to the following equation:

$314.55^{\circ} \mathrm{C} 361.36{ }^{\circ} \mathrm{C}$

$$
\left(\mathrm{C}_{28} \mathrm{H}_{48} \mathrm{O}_{6} \mathrm{~N}_{2}\right)(1)-----------\longrightarrow \text { Complete breakdown-------- } \rightarrow \mathrm{C}_{2} \mathrm{O}_{2} \downarrow+\text { Char }
$$

\subsubsection{Cu (II) complex of Sebacoyl-gabapentin derivative (3):}

While for this derivative- $\mathrm{Cu}(\mathrm{II})$-complex (3) shows two wt. loss steps, and the first one occurs at $314.01{ }^{\circ} \mathrm{C}$ with $80.009 \%$ wt. loss which indicates the breakdown of all the complex (3) but leaving the coordinated part of the derivative (1) with $\mathrm{Cu}$ (II) ion as $\mathrm{Cu}\left(\mathrm{C}_{2} \mathrm{O}_{2}\right)$, indicating the coordination of one molecule of Sebacoyl-gabn. derivative(1) with $\mathrm{Cu}^{2+}$ through carboxylic acid oxygen atoms of two gabapentin molecules, and the wt. loss $80.009 \%$ corresponding to one molecule of gab-sebacoyl derivative (1), but without two molecules of (CO).and that the coordination reaction is $1: 1$ between $\mathrm{Cu}$ (II) ion and the derivative (1).The left char is $20.54 \%$ decomposed further giving two molecules of $\mathrm{CO}$ with $8.305 \%$ practical wt. loss which is near to theoretical value $9.821 \%$, and $\mathrm{Cu}$ atom as residue.The TGAthermogramis shown in Fig.(3). The breakdown of the complex is according to thefollowing equations:

$314.01^{\circ} \mathrm{C}$

1. $\left[\left(\mathrm{C}_{28} \mathrm{H}_{46} \mathrm{~N}_{2} \mathrm{O}_{6}\right) \mathrm{Cu}(\mathrm{II})\right]-----------\longrightarrow($ Breakdown part $)+\mathrm{Cu}\left(\mathrm{C}_{2} \mathrm{O}_{2}\right) \downarrow$ $>450{ }^{\circ} \mathrm{C}$

2. $\mathrm{Cu}\left(\mathrm{C}_{2} \mathrm{O}_{2}\right)$

\subsubsection{Benzoyl-gabn.-derivative(2):}

This derivative shows three wt. loss steps The first one is at $170.85^{\circ} \mathrm{C}$ with $9.294 \%$ wt. loss and we suggest loss of one $\mathrm{CO}$ molecule $(\mathrm{M} . \mathrm{wt}=28.01 \mathrm{~g} / \mathrm{mol}$ ) with theoretical wt. loss $=10.173 \%$. The second step occurs at $234.80 \mathrm{C}$ with $30.105 \%$ wt. lossand it may be $\left(\mathrm{C}_{6} \mathrm{H}_{11}\right)$ as cyclohexene $(\mathrm{M} . w \mathrm{w} .=83.105 \mathrm{~g} / \mathrm{mole})$, and its B.P $=82.9^{\circ} \mathrm{C}$, thus at $234.8^{\circ}$ Cit should be evaporated, with theoretical wt. loss $=30.152 \%$. The second formed compound is suggested to be(B) which is called N-( 2-Hydroxyethyl) benzamide,( MitsuoSekine, Masaki Satoh, Hikaru Yamagata, and Tsujiaki Hata,1980). And the third wt. loss is at $234.80 \mathrm{C}$ with wt. loss $=54.047 \%$ which may correspond to complete breakdown of compound (2b), $\mathrm{C}_{9} \mathrm{H}_{11} \mathrm{NO}_{2}$, (M.wt.= 151.16256), and the theoretical wt. loss $=54.849 \%$.

The remaining is char from $281^{\circ} \mathrm{C}$ up to $900^{\circ} \mathrm{C}$ (2). The details is shown in Fig.(3). And we suggest the following equations for the three steps:

$170.85^{\circ} \mathrm{C}$

1. $\mathrm{C}_{16} \mathrm{H}_{21} \mathrm{NO}_{3}----------\mathrm{C}_{15} \mathrm{H}_{21} \mathrm{NO}_{2}+\mathrm{CO} \uparrow$

(2)A

$197.31^{\circ} \mathrm{C}$

2. $\quad$ A------- $\longrightarrow \quad \mathbf{C}_{9} \mathrm{H}_{11} \mathbf{N ~ O}_{2}+\mathbf{C 6 H 9}(30.105 \%)$

B (Cyclohexene)

$234.80^{\circ} \mathrm{C}$

3. $\quad$ B ------------- $\rightarrow \mathrm{C}_{9} \mathrm{H}_{11} \mathrm{~N} \mathrm{O}_{2}$ (Complete breakdown) $------\longrightarrow \mathrm{Char} \downarrow$

\subsubsection{Cu (II)-complex of Benz. - gabn.- derivative (4):}

It shows first step at $195.15{ }^{\circ} \mathrm{C}$ with $14.292 \%$ wt. loss and we suggest loss of two moles $(\mathrm{CONH})$ radicals(B) (Theoretical. Wt. loss $13.6174 \%$ ) This step indicates that the coordination of $\mathrm{Cu}(\mathrm{II})$ ion is through carboxylate- two oxygen atoms but not with nitrogen atom and oxygen atom of amide group giving probability of tetrahedral or square planar complex. 
In the second step of wt. loss $=54.330 \%$ we suggest loss of two moles of $\left(\mathrm{C}_{6} \mathrm{H}_{11}\right)$ radical(D)and two moles of benzyl radical $\left(\mathrm{C}_{7} \mathrm{H}_{7}\right)(\mathbf{E})$, with theoretical wt. loss $=55.103 \%$, leaving $\mathrm{Cu}\left(\mathrm{CH}_{2}-\mathrm{CO}_{2}\right)_{2}$ as a char,and the thermogram ,Fig. (4) shows these wt. losses, according to the following equations:

$195.15^{\circ} \mathrm{C}$

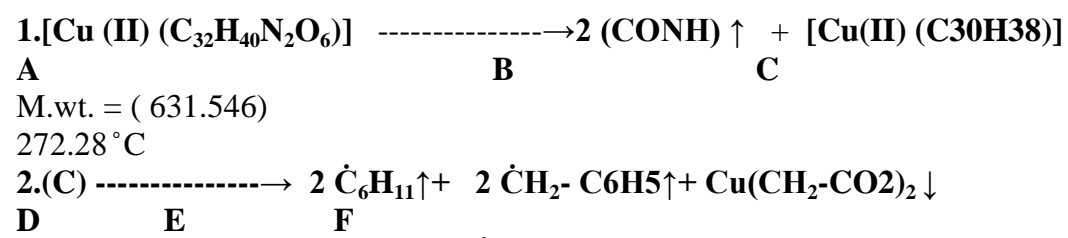

And the third step at about $3700^{\circ} \mathrm{C}$ gives wt. loss of $21.102 \%$ which correspond to the char containing $\mathrm{Cu}$ residue, and evolution of one mole of ethylene and two moles of $\mathrm{CO}_{2}$ which means that the theoretical wt. loss will be $23.946 \%$ : $370^{\circ} \mathrm{C}$

3.(F) ---------- $\rightarrow \mathrm{Cu} \downarrow+\mathrm{C}_{2} \mathrm{H}_{4} \uparrow+2 \mathrm{CO}_{2} \uparrow$

\section{NMR spectra:}

\subsection{Sebacoyl- gabapentin derivative (1):}

${ }^{1}$ HNMR spectrum of sebacoyl- gabapentin derivative (1) shows cyclohexylprotons bands of gabapentin at range (1.8 2.2) $\mathrm{ppm}$, and at $2.8 \mathrm{ppm}$ for $\mathrm{CH}_{2}$ - protons attached to carboxylic group of gabapentin that compared to the free gabapentin which occurs at (1.33-1.479) ppm and at $2.415 \mathrm{ppm}$ for $\mathrm{CH}_{2}$ group attached to carboxylic group (Hussain E.A. et al 2017, Al-Mudhaffar D.M. et al 2018), this shift is due to coordination with sebacoylchroride. Single sharp band occurs at about $8 \mathrm{ppm}$ due to $(-\mathrm{NH})$ amide proton due to condensation of gabapentin with sebacoyl chloride. Hydroxyl proton gives broad band at about $12.9 \mathrm{ppm}$. Another methyl group protons $\left(\mathrm{CH}_{2}-\mathrm{NH}_{2}\right)$ occurs at $2.503 \mathrm{ppm}$ that correspond to gabapentin molecule. Another bands occur in the range (1.4 -2.9) ppm due to sebacoyl group but are little shifted as result of condensation with gabapentin (www.hanhonggroup.com/en/) The spectrum is shown in Fig(5), and detailed data in Table (2).

Table (2) NMR chemical shifts of Gabapentin derivatives (1) \& (2)

\begin{tabular}{|c|c|c|c|}
\hline $\begin{array}{l}\text { Compound } \\
\text { no. }\end{array}$ & Structure & ${ }^{1}$ H NMR (ppm) & $\begin{array}{ll}{ }^{13} \mathbf{C} & \text { NMR } \\
(\mathbf{p p m}) & \end{array}$ \\
\hline (1) & & $\begin{array}{l}\mathrm{H} \text { (Cycl.-Gabn.): (1.8- } \\
2.8), \quad \mathrm{H} \quad(\mathrm{HN}- \\
\text { amide):8.393, } \mathrm{H}\left(\mathrm{CH}_{2}-\right. \\
\mathrm{NH}): 2.4, \mathrm{H}(\mathrm{Sebacoyl}) \\
(1.4-2.9), \quad \mathrm{H}(\mathrm{CH} 2- \\
\text { carboxylic): } 2.5\end{array}$ & $\begin{array}{l}\text { (Sebl.): } \text { C1: } \\
\text { 173.28, C3:25, } \\
\text { C4 : 24.8, C2: } \\
\text { 39.694, C5: 23, } \\
\text { C-O-OH: 175, } \\
\text { C-NH: 40.25. }\end{array}$ \\
\hline (2) & & 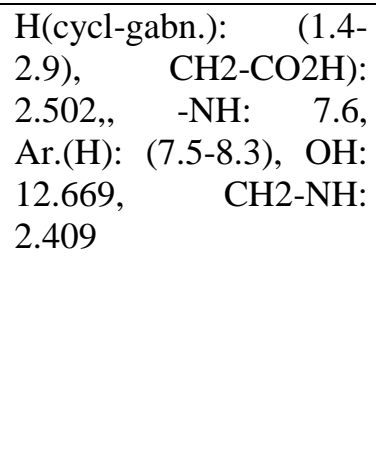 & $\begin{array}{l}\text { (m-6C- } \\
\text { Cyclohexan) } \\
(25.821- \\
39.695), \\
(\mathrm{S}-\mathrm{C}-\mathrm{NH}) \\
: 40.244, \\
(\mathrm{~S}-\mathrm{C}-\mathrm{COOH}) \\
: 40.521, \\
(\mathrm{~m}-6 \mathrm{C}-\mathrm{Ar}) \quad: \\
127.76- \\
135.183),\end{array}$ \\
\hline
\end{tabular}




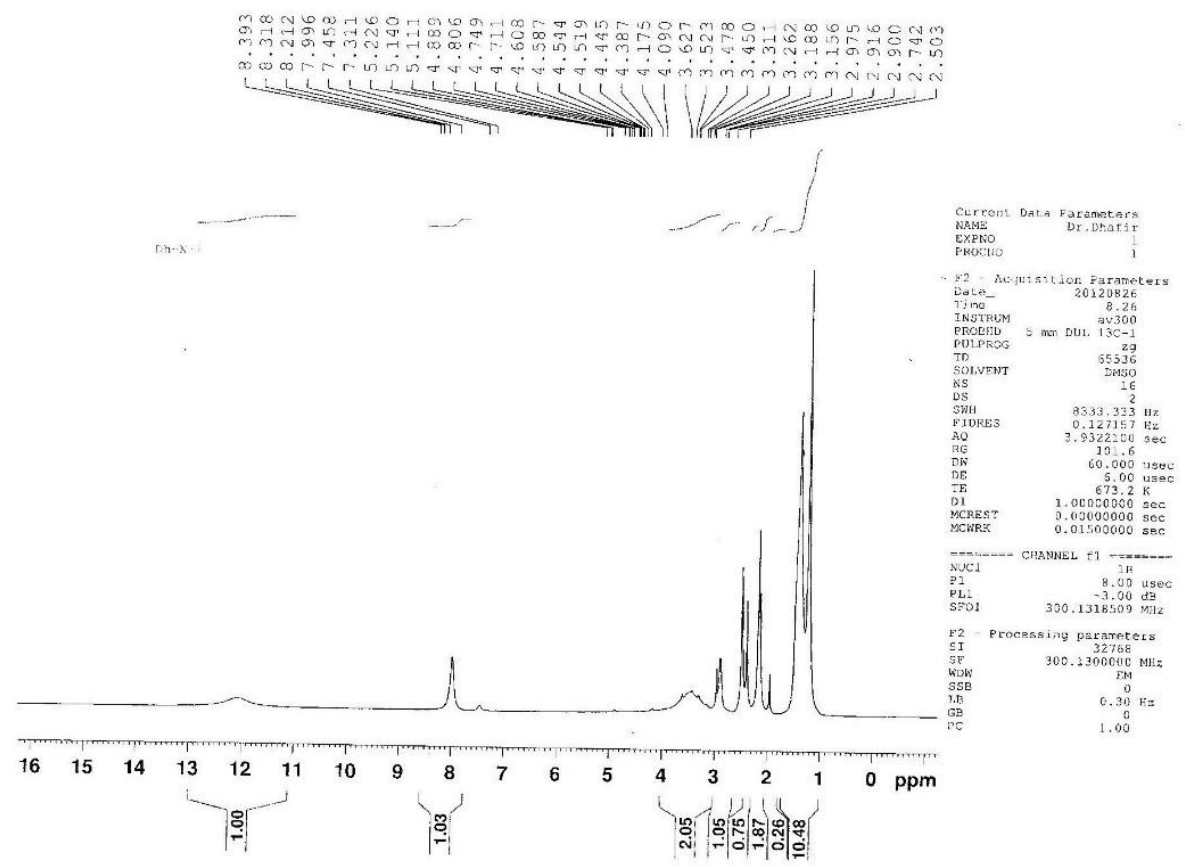

Fig.(5): ${ }^{1}$ HNMR spectrum of Sebacoyl-gabn.-

derivative (1)

${ }^{13} \mathrm{C}$ NMR spectrum for this derivative (1)shows the band of gabapentin-carbon amide atoms at 173.28 ppm but with little shift due to the condensation withsebacoylchloride and for free sebacoyl chloride occurs at $173.60 \mathrm{ppm}$.Single band appears at $174.92 \mathrm{ppm}$ may beattributed to carbon of carboxyl carbonyl group. (Al-Mudhaffar Dh. M. et al 2018). Carbon-amide signal occurs at $173.28 \mathrm{ppm}$. Another two bands occur at $25 \mathrm{ppm}$ and $24.8 \mathrm{ppm}$ due to $\mathbf{C}_{3}$ and $\mathbf{C}_{\mathbf{4}}$ respectively of sebacoyl group with little shift than that of free sebacoyl chloride which occur at $28.78 \mathrm{ppm}$ and 28.32 ppm respectively, due to coordination in forming the derivative (1)(www.hanhonggroup.com/en/). This spectrum is shown in Fig.(5), and the detailed data is given in Table (3):<smiles>C=I(Cl)(Cl)CSSCCCCCCCC</smiles>

\section{Sebacoyl Chloride}

\subsection{Benzoyl- gabapentin derivative (2):}

${ }^{1} \mathrm{H}$ NMR spectrum of this derivative (2)shows cyclohexane protons of gabapentin bands at (1.2-2.9) ppm , and at 3.5 ppm for methyl $\left(\mathrm{CH}_{2}-\right)$ which attached to cyclohexylic group of gabapentin compared to free gabapentin molecule occurs at $2.629-1.33) \mathrm{ppm}$ and at $2.415 \mathrm{ppm}$ respectively.Hydroxyl group of gabapentin occurs at $7.6 \mathrm{ppm}$ embedded with the aromatic protons bands of benzoyl group which gives the aromatic protons bands in the range (7.5-8.3) ppm ( Al-Mudhaffar Dh. M. et al 2018). Hydroxyl group occurs at $12.7 \mathrm{ppm}$, and for the free gabapentin molecule gives bands in the range (12.22-12.62)ppm and this shift occurs due to coordination. The ${ }^{1}$ HNMR spectra is shown in Fig.(6), and the detailed data in Table (2). 


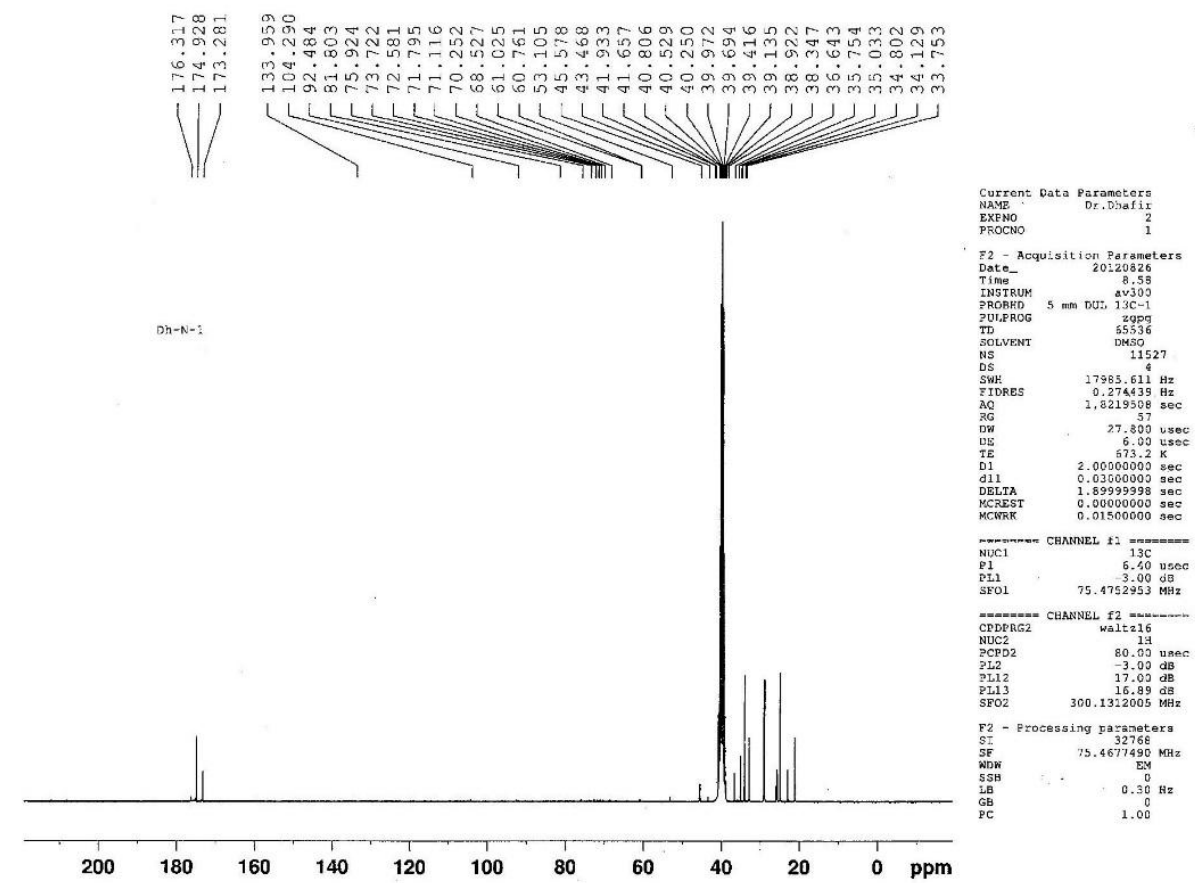

Fig. (6) ${ }^{13} \mathrm{C}$ NMR spectrum of Sebacoyl- gabn.

derivative (1)

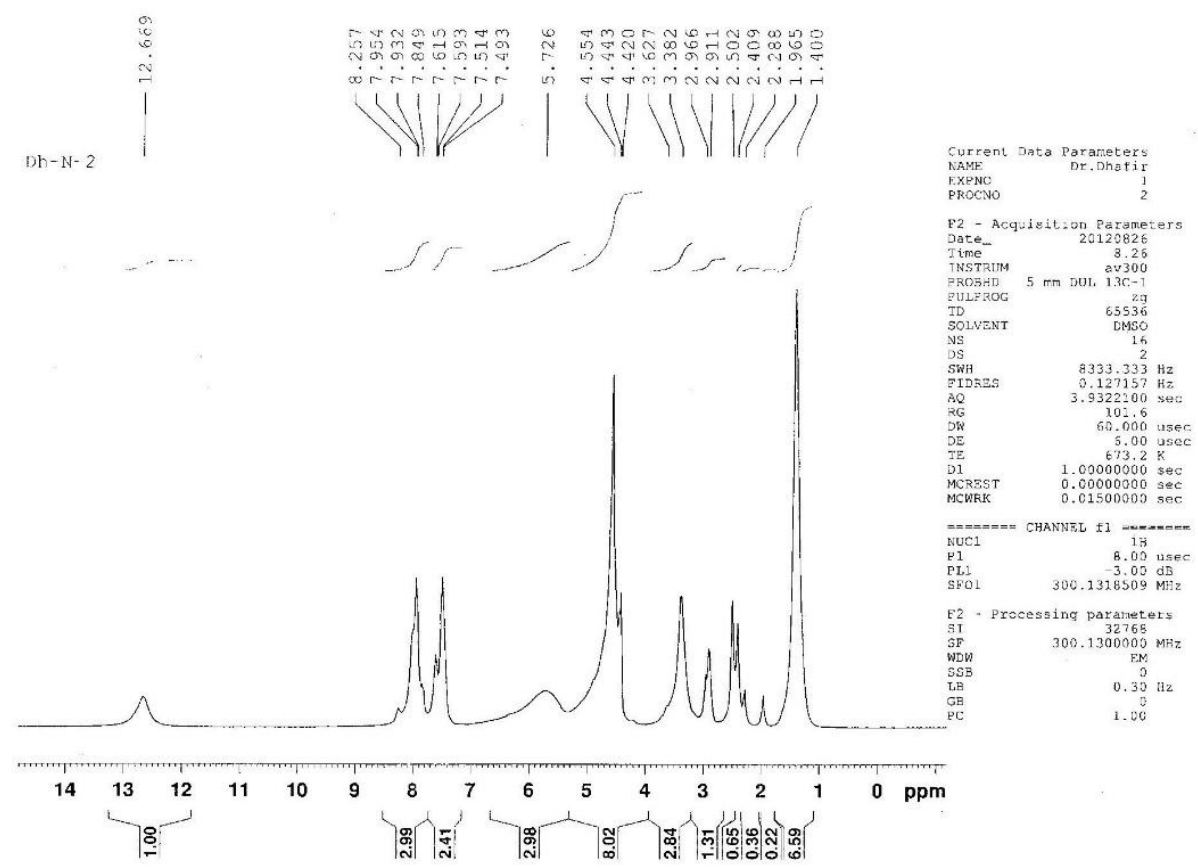

Fig.(7): 'HNMR spectrum of Benzoylgabn.derivative (2) 


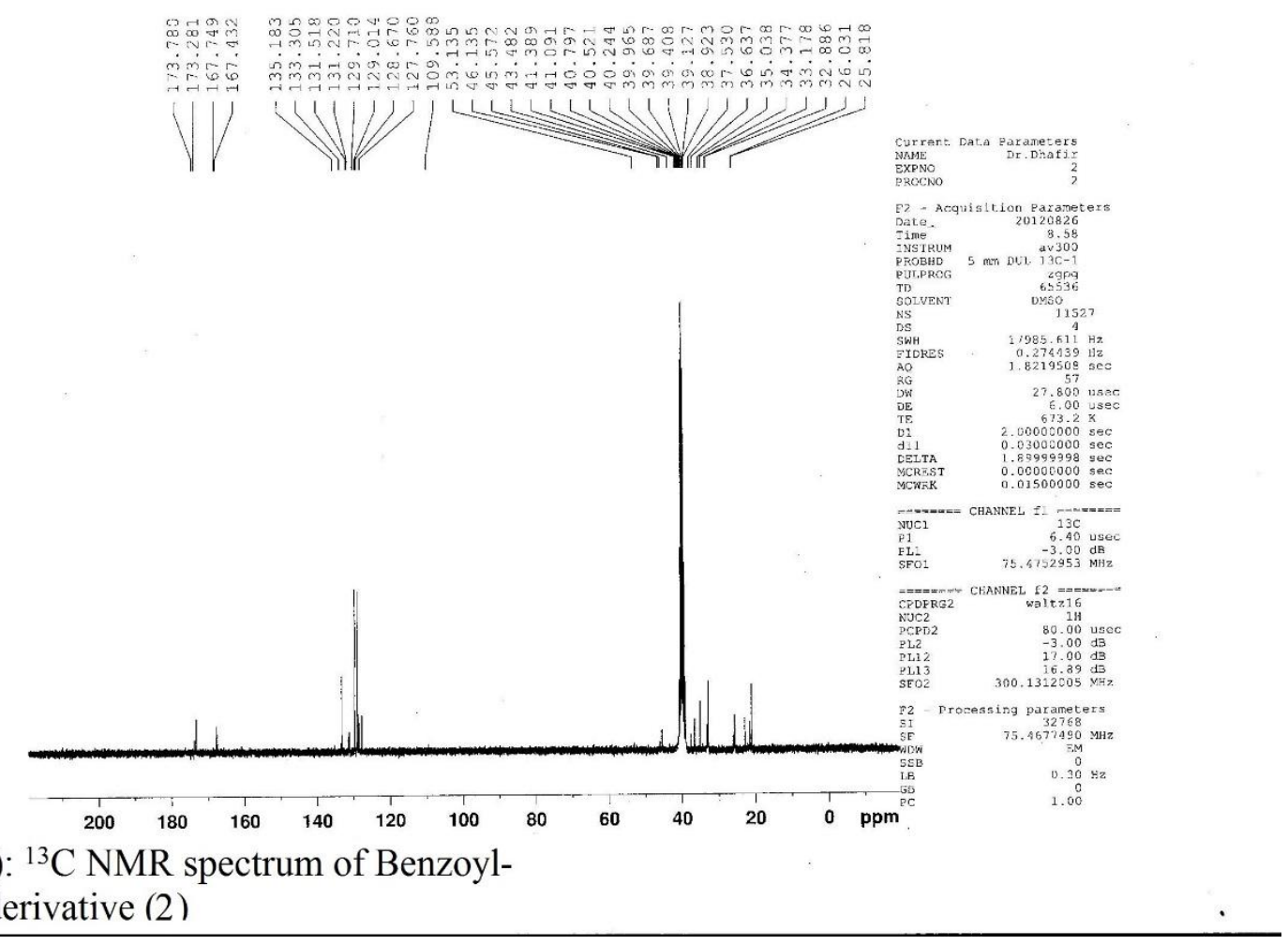

${ }^{13} \mathrm{C}$ NMR of this derivative (2)shows the characteristic bands for cyclohexyl carbon atoms at (21-39) ppm with little shift due to condensation with benzoyl chloride. Aromatic carbon atoms of benzoyl group occur in the range (127.76135.183) ppm whereas for the free benzoyl chloride occur at (129-135.3) pm. Carbonyl carbon atom of benzoyl group shows band at about $168 \mathrm{ppm}$ and for that of the free benzoyl chloride occurs at $167.9 \mathrm{ppm}$. The spectrum shows carbon atoms bands of cyclohexylic gabapentin group in the range(21.08-37.53) ppm nearly similar to that of free gabapentin- cyclohexyl carbon atoms which occur in the range (21.1-32.2) ppm with little shift due to the condensation with benzoyl chloride (Wishart DS, et al.: HDMB. Epub 2008 Oct).

From IR spectra, CHN, thermal analysis, and NMR spectra we confirm the formation of gabapentin derivatives, i.e. derivative (1) as(sebacoyl- gabapentin)derivative with the following formula:

(1)

And(benzoyl-gabapentin) derivative (2)with the following formula: 
In addition, for $\mathrm{Cu}$ (II) complexes (3)and (4), copper ion forms two coordinated complexes, either tetrahedral or square planar through carboxylic oxygen atoms, according to soft and hard (acid-base)criteria, as in the followings:

[(Sebacoyl- gabapentin) Cu(II)]-Complex:(3)

\section{[Benzoyl-gabapentin) $\left.{ }_{2} \mathrm{Cu}(\mathrm{II})\right]-$ Complex(4)}

\section{Conclusion:}

The present measurements by IR, CHN, ${ }^{1} \mathrm{HNMR},{ }^{13} \mathrm{C}$ NMR, and TGA confirm the formation of the two gabapentin derivatives by green chemistry and their copper(II) complexes. These compounds may exhibit antioxidant and/ or anticancer activities, which need further study..

\section{Acknowledgment}

I would like to gratitude College of Science /Basrah University, for supporting the work. Our thanksto AL-Albeit University (Jordan) for doing CHN and NMR measurements. Thanks for Science College, Muthana University/ Iraq for doing thermal analysis.

\section{References}

Ahmad N. and Sewwell D. E.(2017), Gabapentin and its salicylaldehyde derivative alleviate allodynia and hypoalgesia in a cisplatin-induced neuropathic pain model, European Journal of pharmacology, 814, 302312.

Al-Mudhaffar Dh. M. H., Al- Mowali A. H., Al-Badran U.H., ( 2018 ), Synthesis, Characterization, Biological activity and Antioxidant Study of Gabapentin Derivatives and their Complexeswith [ $\mathrm{Cu}(\mathrm{II}), \mathrm{Zn}$ ( II ) ], International Journal of Applied Science and Technology, 8, No.2, June.

Amirani M. \& Mohammadi M. (2018), Gabapentin-base Synthesis and Theoretical Studies of Biologically Active Compounds: N-cyclohexyl-3-oxo-2-(3-oxo-2-azaspiro[4.5] decan-2-yl)-3-arylpropanamides and N(tert-butyl)-2-(3-oxo-2-azaspiro[4.5]deca2-yl)-2-arylacetamide derivatives, Journal of Molecular Structure, 1152, 44-52.

Amshumli MK, Abhilash N, MallikarjunagoudaPatil, (15 Jun 2018),Unprecedented Example of Metal Complexes With 1-Aminomethyl-1-Cyclohexane Acetic Acid, International Journal of Chemical Sciences, 16, issue 4. 
Goa KL, Sorkin EM (September 1993). "Gabapentin. A review of its pharmacological properties and clinical potential in epilepsy".Drugs, 46 (3): 409-427. PMD 7693432.

Ibid (2015),Gabapentin. The American Society of Health- System Pharmaceuticists. Drugs.com on 19 August 2017. Retrieved 23 Oct. 2015.

Hekmat S., Balalaie S., Ramezanpour S., Rominger F., Vavsari V. and Kabiri-Fard H. (2017), SBA-Pr-SO ${ }_{3} \mathrm{H}$ : an efficient catalyst for the combinatorial synthesis of functional 2-aryl-4-quinazolinones using unusual $\gamma$ amino acids, Journal Of ChemicalSociety, 14, 833-841.

Hussain E.A., Kanwal N., Khan I. U., Mutahir S. and Yar M. (2017), Green and Facile Reaction of Gabapentin with Sulfonyl Chlorides to Synthesize Lactams and Sulfonamides Derivatives in Aqueous Medium, Letters in Organic Chemistry, 15, 163-170.

Hussain, Erum A, NosheenKanwal, Islam Mtahir, Muhammad A. Khan, Maksood Ahmed, Arshad Mahmod, OnuurSahin, Mehmet Akkurt and Muhammad Yar (March 2018), Green and Facile Reaction of Gabapentin with Sulphonyl Chlorides to Synthesize Lactams and Sulphonamides Derivatives in Aqueous Medium, Letters in Organic Chemistry, vol. 15, No.3, , 163-170.

MitsuoSekine, Masaki Satoh, Hikaru Yamagata, and TsujiakiHata,(1980),The Journal of Organic Chemistry, 45,(21), $4162-4167$

Shokohi-pour Z, (2016), A novel Schiff base derived from the gabapentin drug and copper (II) complex : Synthesis, characterization, interaction with DNA protein and cytotoxic activity, Journal of photochemistry and photobiology, B.Biology, 162, 34-44.

Wijemanne S, Jankovic J (June 2015). "Restless legs syndrome: clinical presentation diagnosis and treatment". Sleep Medicine 16(6): 678-690. PMID 25979181.

Wishart DS, Knox C, Guo AC, Eisner R, Young N, et al,: HMDB: a knowledgebase for the human metabolome. Nucleic acid Res. 2009 Jan; 37(Database issue):D603-10. Epub 2008 Oct 25. [PubMed. 18953024].

www.hanhonggroup.com/nmr/nmr_en/B35160.html. 